\title{
Low temperature hydrogenation and hydrodeoxygenation of oxygen-substituted aromatics over Rh/silica: part 1: phenol, anisole and 4-methoxyphenol
}

\author{
Feras Alshehri $^{1,2} \cdot$ Clement Feral $^{1} \cdot$ Kathleen Kirkwood $^{1} \cdot$ S. David Jackson ${ }^{1}$ (D)
}

Received: 23 May 2019 / Accepted: 3 July 2019 / Published online: 9 July 2019

(c) The Author(s) 2019

\begin{abstract}
The hydrogenation and competitive hydrogenation of anisole, phenol and 4-methoxyphenol was studied in the liquid phase over a $\mathrm{Rh} /$ silica catalyst at $323 \mathrm{~K}$ and 3 barg hydrogen pressure. The rate of conversion of the reactants to products gave an order of anisole $\gg$ phenol $>$ 4-methoxyphenol with hydrogenation and hydrodeoxygenation products being produced. Anisole, the most reactive substrate, was rapidly converted to methoxycyclohexane, cyclohexane, cyclohexanone and cyclohexanol, while phenol was hydrogenated to cyclohexanone, cyclohexanol and cyclohexane. In both cases cyclohexanol was produced as a secondary product from cyclohexanone hydrogenation. The yield of cyclohexane, the hydrodeoxygenation (HDO) product was $>20 \%$ from both reactants and was formed as a primary product from the aromatic species. Hydrogenation of 4-methoxyphenol was selective to 4-methoxycyclohexanone with no alcohol formation, while the hydrogenolysis products revealed that the catalyst was more active for demethoxylation than dehydroxylation. A comparative strength of adsorption was determined from competitive hydrogenation and gave an order of anisole $>$ phenol $>4$-methoxyphenol. Competitive, pair hydrogenation inhibited HDO and stopped cyclohexane from being produced from phenol and 4-methoxyphenol, although it was still produced from anisole. An increased rate of hydrogenation for 4-methoxyphenol was observed for competitive reactions with phenol and anisole but not when all three reactants were present. In contrast to the pair reactions, when all three reactants were present HDO occurred with all aromatics producing cyclohexane. Replacing hydrogen with deuterium revealed an inverse kinetic isotope effect for ring hydrogenation of 4-methoxyphenol but not phenol or anisole, which both had a positive KIE.
\end{abstract}

Keywords Hydrogenation $\cdot$ Hydrodeoxygenation $\cdot$ Rhodium/silica $\cdot$ Anisole $\cdot$ Phenol · 4-Methoxyphenol

Electronic supplementary material The online version of this article (https://doi.org/10.1007/s1114 4-019-01630-9) contains supplementary material, which is available to authorized users.

Extended author information available on the last page of the article 


\section{Introduction}

Hydrogenation and hydrodeoxygenation (HDO) of bio-oils is currently a significant research undertaking $[1,2]$ and a wide range of conditions and catalysts have been investigated [3]. In this paper we will report on the liquid-phase hydrogenation and HDO of anisole, phenol and 4-methoxyphenol. Anisole and phenol were chosen because they are typical of species found in bio-oil [4], while 4-methyoxyphenol was chosen as it had both functional groups and it allowed a comparison with both phenol and anisole. Our interest lay in examining the behavior of these compounds when reacted on their own but also in a competitive environment. In a practical process it is unlikely that bio-oil components will be separated and then treated, so we were interested to understand how a system would react if, instead of a single feed, it was given a co-feed. Although typically HDO is performed at high temperatures $(>473 \mathrm{~K})$ we were interested in low temperature HDO $(<373 \mathrm{~K})$. In general high temperature HDO gives aromatics as products [5] however at low temperatures there would be significant hydrogenation of the aromatic ring giving cyclohexyl species rather than aromatics. This would allow the option of choosing a process to deliver either saturated or unsaturated products.

Phenol hydrogenation is an important industrial process for the production of cyclohexanone and cyclohexanol. Cyclohexanone is a key intermediate in the synthesis of nylon and polyamide resins [6], while cyclohexanol is used widely in fine chemistry and perfume industry [7]. Other products such as benzene and cyclohexane [8-11] are also mentioned in the literature and have been related to the type of catalyst and solvent [9]. Giraldo et al. [9] investigated the vapor phase hydrogenation of phenol, after dissolving it in different solvents, over $\mathrm{Rh} / \mathrm{SiO}_{2}$. They used cyclohexane, benzene, toluene, and ethanol as solvents and concluded that higher phenol conversion could be achieved when cyclohexane was used as the solvent and that cyclohexanone selectivity was not affected by the nature of solvent when cyclohexane, benzene or toluene was used. There is general agreement that phenol hydrogenation proceeds in a sequential process, if performed under moderate conditions, from phenol to cyclohexanone to cyclohexanol [12, 13]. The reaction can follow a hydrogenolysis route or a hydrogenation route. The hydrogenolysis route involves the formation of benzene after the cleavage of the $\mathrm{OH}$ group. Benzene is then hydrogenated to cyclohexane. The hydrogenation route follows the formation of cyclohexenol, which isomerizes to cyclohexanone. Both isomers can subsequently be hydrogenated to form cyclohexanol. Cyclohexane can then be formed from the hydrogenolysis of cyclohexanol.

Anisole hydrogenation has been studied in the literature [14-19] but few of these studies involve an examination of the kinetics and mechanism. In most reported anisole hydrogenation reactions, methoxycyclohexane is the major product with selectivity ranging from 70 to $100 \%$ depending on catalyst, solvent and parameters applied [15]. Other products that have been cited include cyclohexanone, cyclohexanol and cyclohexane. Mevellec et al. [16], for example, studied the hydrogenation of different aromatic compounds over a colloidal rhodium 
suspension of $\mathrm{SiO}_{2}-\mathrm{Rh}^{0}$ nanoparticles. They found that anisole was selectively hydrogenated to methoxycyclohexane at $293 \mathrm{~K}$ and $1 \mathrm{~atm}$ hydrogen pressure. In another study, Fang et al. [17] used a polyvinylpyrrolidone-Ru catalyst system to study the hydrogenation of aromatics, olefins and carbonyl containing compounds. They found that anisole was hydrogenated to methoxycyclohexane (70\%), cyclohexane (16\%) and cyclohexanol (14\%). They used decane as a solvent at $353 \mathrm{~K}$ under $4 \mathrm{MPa}$ hydrogen pressure. Denicourt-Nowicki et al. [18] used bipyridines to stabilise Rh NPs during the hydrogenation of anisole. They produced $77 \%$ methoxycyclohexane and 23\% cyclohexanone with $100 \%$ anisole conversion. Anisole hydrogenation over rhodium [20] has two proposed routes, a direct hydrogenation to the corresponding cyclic form, methoxycyclohexane and a route to the formation of cyclohexanone and/or cyclohexanol. Cyclohexanone was suggested to form via the formation of an intermediate, methoxycyclohexene [20, 21], which had been detected by Widegren and Finke [20] with 2-8\% selectivity.

4-Methoxyphenol hydrogenation over heterogeneous catalysts has not been subject to any significant study however there are examples in a patent [22]. In these examples 4-methoxyphenol is converted to 4-methoxycyclohexanone with $93 \%$ yield at $\sim 423 \mathrm{~K}$ with 5 bar hydrogen over an alkali modified P/C catalyst.

\section{Experimental}

The catalyst used throughout this study (2.5\% Rh/silica, M01074) was supplied and characterized by Johnson Matthey. The catalyst was prepared using an incipientwetness technique using aqueous rhodium chloride salts and a silica support supplied by Davison Catalysts. The catalysts were dried overnight at $333 \mathrm{~K}$ and reduced in flowing hydrogen at $473 \mathrm{~K}$ for $2 \mathrm{~h}$ before being cooled and exposed to air. The catalyst had a surface area of $311 \mathrm{~m}^{2} \mathrm{~g}^{-1}$ and a pore size of $13.9 \mathrm{~nm}$, both of which were measured using standard BET methodology. The metal surface area was measured by hydrogen chemisorption (reproducibility $\pm 0.5 \mathrm{~m}^{2} \mathrm{~g}^{-1}$ ) and gave an area of $4.7 \mathrm{~m}^{2} \mathrm{~g}^{-1}$ and a dispersion of $43 \%$, from which an average metal crystallite size of $2.6 \mathrm{~nm}$ was calculated.

The hydrogenation reactions were performed in a $500 \mathrm{~cm}^{3}$ Büchi autoclave stirred tank reactor supplied with an oil heating jacket. The temperature was measured in the liquid slurry with accuracy of $\pm 0.1 \mathrm{~K}$ and controlled by a high temperature oil circulator to $\pm 0.5 \mathrm{~K}$. The reactor was equipped with a variable speed stirrer connected to a magnetic drive that could be controlled to $\pm 5 \mathrm{rpm}$. The pressure and gas flow was controlled by a Büchi press-flow gas controller with an accuracy of $\pm 0.01 \mathrm{bar}$ and measurement of the consumed hydrogen to $0.1 \mathrm{mmol}$. The gas controller was used to achieve a constant hydrogen pressure in the autoclave. The experimental methodology charged the catalyst $(100 \mathrm{mg})$ into the autoclave with $320 \mathrm{ml}$ of isopropyl alcohol (IPA). The solvent was degassed and the autoclave purged with nitrogen before heating to the reduction temperature. During the heating the solution was slowly stirred (300 rpm). The catalyst was reduced in situ at $343 \mathrm{~K}$ by sparging hydrogen gas at a flow rate of $280 \mathrm{~cm}^{3} \mathrm{~min}^{-1}$ through the mixture for $0.5 \mathrm{~h}$, while maintaining the stirrer speed at $300 \mathrm{rpm}$. After the reduction process was 
complete, the stirrer was turned off and the reactor was purged with nitrogen twice and pressurized to 1 barg pressure. The flow of hydrogen, deuterium or inert gas to the reactor was measured by the gas controller, which was also used to measure the hydrogen or deuterium consumed in the reaction. The system was then cooled to the desired reaction temperature under slow stirring. Once at the required temperature $(303-333 \mathrm{~K})$ the stirrer was turned off and $1.0 \mathrm{ml}$ of phenol $(10.6 \mathrm{mmol}$, Sigma-Aldrich $\geq 99 \%$ ), anisole (methoxybenzene, $9.2 \mathrm{mmol}$ Sigma-Aldrich 99\%), or 4-methoxyphenol (8.0 mmol, Sigma-Aldrich 99\%) in $10 \mathrm{ml}$ of isopropyl alcohol was added to the reactor vessel to give a total reaction volume of $330 \mathrm{ml}$. This gives a ratio of reactant:surface site of $\sim 1000: 1$. For competitive reactions $1 \mathrm{ml}$ of each reactant as appropriate was added to the reactor in $10 \mathrm{ml}$ of IPA. The solution was stirred at $1000 \mathrm{rpm}$ to thoroughly mix the components. The stirrer was then turned off and the reactor pressurized with nitrogen to 1 barg before a $2.5 \mathrm{ml}$ sample was withdrawn. The reactor was then de-pressurized and purged twice with hydrogen before pressurizing with hydrogen to the desired reaction pressure (1-5 barg). Once at pressure, the reaction was started by switching the stirrer on at $1000 \mathrm{rpm}$ : this was taken as time zero of the reaction. The reaction was followed by withdrawing samples of $2.5 \mathrm{ml}$ at different time intervals during the reaction. Mass balance was $100 \pm 2 \%$. Analysis of the liquid samples was performed using a Thermo Finnigan Focus gas chromatograph equipped with an AS 3000 autosampler. The column used was an HP-1701, $30 \mathrm{~m} \times 0.25 \mathrm{~mm} \times 1 \mu \mathrm{m}$ film thickness. Standard tests were performed to ensure the absence of mass transport control.

\section{Results and discussion}

Full details of the reaction profiles and the analysis of the data are shown in the Supplementary Data file, while summary/key information is reported in the paper. The three reactants were hydrogenated over a range of temperatures, pressures and concentrations to determine apparent activation energies and orders of reaction (Table 1). No reaction was detected using the silica support in the absence of metal. Anisole had the fastest rate of hydrogenation and underwent hydrogenolysis as well as hydrogenation (Fig. 1). Note that no cyclohexanone hydrogenation to cyclohexanol occurred until almost all the anisole was converted.

Table 1 Kinetic data for hydrogenation of anisole, phenol and 4-methoxyphenol

\begin{tabular}{llllc}
\hline Compound & $\mathrm{Ea}\left(\mathrm{kJ} \mathrm{mol}^{-1}\right)$ & Order in $\mathrm{H}_{2}$ & Order in organic & $\mathrm{k}^{\mathrm{a}}\left(\mathrm{min}^{-1}, \times 10^{-3}\right)$ \\
\hline Anisole & $46 \pm 0$ & $1.1 \pm 0.3$ & $0.2 \pm 0.2$ & $74.8 \pm 4.8$ \\
Phenol & $27 \pm 5$ & $1.0 \pm 0.3$ & $0.0 \pm 0.3$ & $14.7 \pm 0.2$ \\
4-methoxyphenol & $54 \pm 2$ & $\mathrm{NM}^{\mathrm{b}}$ & $\mathrm{NM}^{\mathrm{c}}$ & $6.4 \pm 0.1$ \\
\hline
\end{tabular}

${ }^{\mathrm{a}} \mathrm{k}$, first order rate constant measured at $323 \mathrm{~K}, 3$ barg and $\sim 9$ mmol reactant

${ }^{\mathrm{b}} N M$ not measured

${ }^{\mathrm{c}}$ Visual inspection suggested zero order 


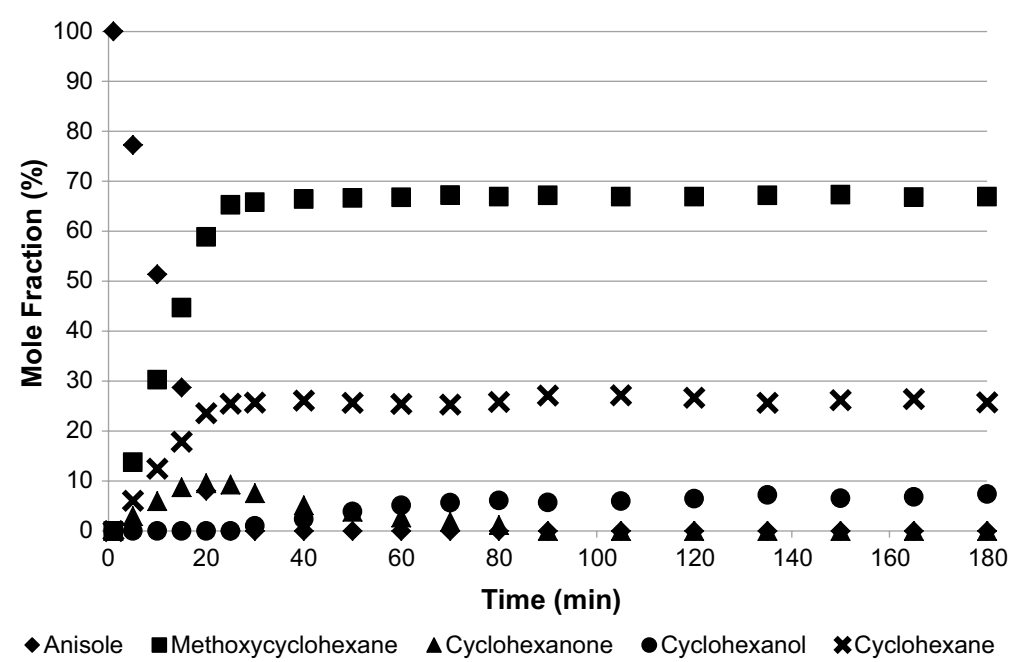

Fig. 1 Reaction profile of anisole hydrogenation. Conditions, $323 \mathrm{~K}, 9 \mathrm{mmol}, 3 \mathrm{barg}$

The hydrogenation of anisole rapidly went to completion at all temperatures studied and as expected the major product was the ring-hydrogenated species, methoxycyclohexane. Cyclohexanone was formed as an intermediate (via keto-enol tautomerism) and was hydrogenated to cyclohexanol but only once all the anisole was hydrogenated, suggesting that anisole blocked re-adsorption of cyclohexanone, indicating that there is no direct route from anisole to cyclohexanol. The hydrogenolysis/HDO product, cyclohexane, was also formed in moderate yield: indeed even at $303 \mathrm{~K}$ there was $\sim 20 \%$ yield of cyclohexane. When cyclohexane was formed an equivalent amount of methanol was also detected. The most recent studies of anisole hydrogenation over supported $\mathrm{Rh}$ nanoparticles in the literature reported no evidence of hydrogenolysis even at high hydrogen pressure, with $100 \%$ yield of methoxycyclohexane $[16,23]$. However other studies have shown the formation of cyclohexanol [24] in moderate yield $(\sim 16 \%)$. In contrast our results show that although hydrogenation is the primary process occurring there was also significant hydrogenolysis (Scheme 1). As the temperature was increased there was a change in the reaction selectivity between hydrogenation and hydrogenolysis. At low temperature hydrogenation was favored but as the reaction temperature was increased hydrogenolysis of the $\mathrm{Ar}-\mathrm{OCH}_{3}$ bond (leading to formation of cyclohexane) and $\mathrm{ArO}-\mathrm{CH}_{3}$ bond (leading to the formation of cyclohexanol) was increasingly favored. This is shown in Fig. 2.

This behavior has been reported in the literature for anisole hydrogenation over ruthenium catalysts [16] but not rhodium. Both $\mathrm{Ar}-\mathrm{OCH}_{3}$ and $\mathrm{ArO}-\mathrm{CH}_{3}$ bonds were broken but the system was more active for hydrogenolysis of the $\mathrm{Ar}-\mathrm{OCH}_{3}$ bond (demethoxylation, Fig. 2) even though it is stronger than the $\mathrm{ArO}-\mathrm{CH}_{3}$ bond $\left(\sim 419 \mathrm{~kJ} \mathrm{~mol}^{-1}\right.$ c.f. $\left.\sim 381 \mathrm{~kJ} \mathrm{~mol}^{-1}\right)$. Methanol was detected as a by-product and the yield matched that of cyclohexane. The production of cyclohexane does not appear to go through benzene (none detected) or the hydrogenolysis of 


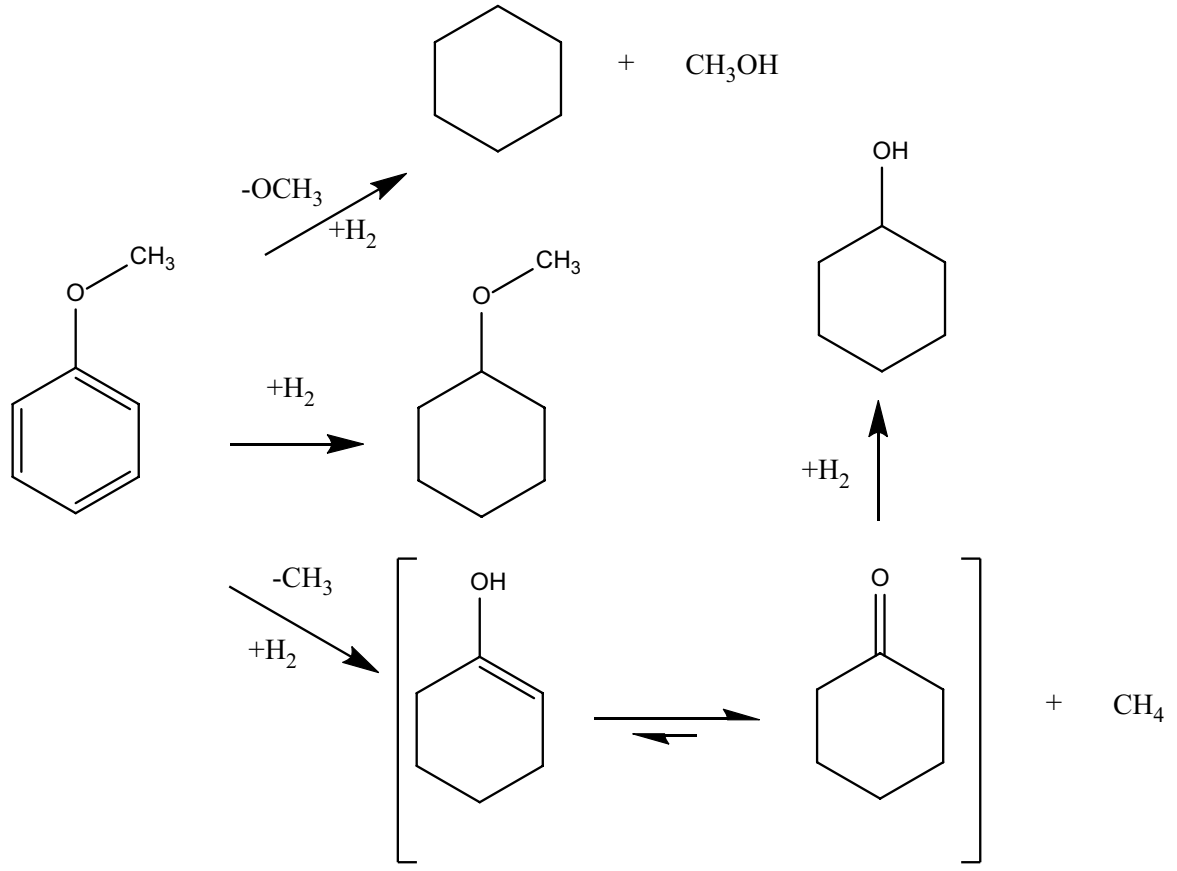

Scheme 1 Hydrogenation and hydrodeoxygenation of anisole

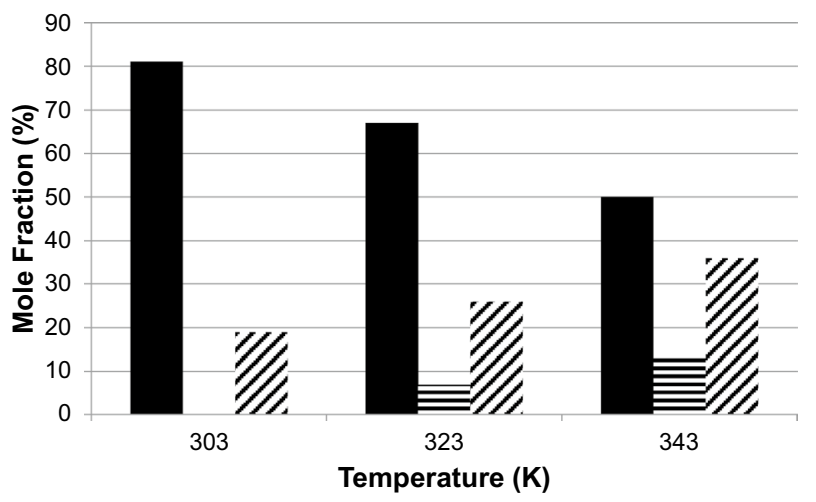

- methoxycyclohexane झcyclohexanol "cyclohexane

Fig. 2 Selectivity obtained from anisole hydrogenation as a function of temperature. Anisole conversion was $100 \%$. Conditions: 3 barg $\mathrm{H}_{2}, 9$ mmol

cyclohexanol, which was stable under reaction conditions, suggesting a direct surface route from anisole to cyclohexane. The absence of benzene was also noted in a hydrodeoxygenation (HDO) study of anisole at $473 \mathrm{~K}$ and 52 bar hydrogen [25] over nickel, ruthenium and palladium catalysts, where cyclohexane was the major product. It was proposed that the route to deoxygenation was via hydrogenation 
of anisole to methoxycyclohexane followed by dealkylation. However this route was not active under our conditions ( $323 \mathrm{~K}, 3 \mathrm{barg}$ ) as there was no evidence of methoxycyclohexane undergoing dealkylation (Fig. 1). This is in agreement with a study over platinum [26] where it was shown that methoxycyclohexane was stable with respect to demethoxylation. Therefore cyclohexanone, and subsequently cyclohexanol, were formed by demethylation ( $\mathrm{ArO}-\mathrm{CH}_{3}$ bond breaking) of anisole giving a phenolic surface intermediate (no phenol detected in solution) that is rapidly hydrogenated. This consistent with HDO of anisole at $573 \mathrm{~K}$ and $34 \mathrm{bar}$ hydrogen, where demethylation to phenol was the primary HDO reaction [27]. The splitting of the ArO- $\mathrm{CH}_{3}$ bond indicates that both oxygen and methyl group are in contact with the surface.

Hydrogenation of phenol is shown in Fig. 3. The activation energy of $27 \pm 5 \mathrm{~kJ} \mathrm{~mol}^{-1}$ agrees well with the literature $\left(32 \mathrm{~kJ} \mathrm{~mol}^{-1}\right)$ [28]. The hydrogenation of phenol gave cyclohexanone and cyclohexanol, while cyclohexane was the hydrogenolysis product at $20 \%$ yield at $100 \%$ conversion. Note that the presence of phenol did not inhibit cyclohexanone hydrogenation, in contrast to anisole, suggesting that phenol is more weakly adsorbed than anisole, which is consistent with the reaction orders detailed in Table 1 . Nevertheless the difference was somewhat surprising as it may have been expected that the extra steric bulk of the methoxy group would tend to reduce the strength of interaction. The rate of phenol hydrogenation was significantly less than the rate of anisole hydrogenation. Studies of phenol hydrogenation over rhodium catalysts have used supercritical carbon dioxide as the solvent $[28,29]$. In these studies only cyclohexanol and cyclohexanone were formed, there were no reports of the formation of cyclohexane. Nevertheless cyclohexane has been reported as a product of HDO of phenol over rhodium albeit at higher temperatures (573 K) [30] and direct

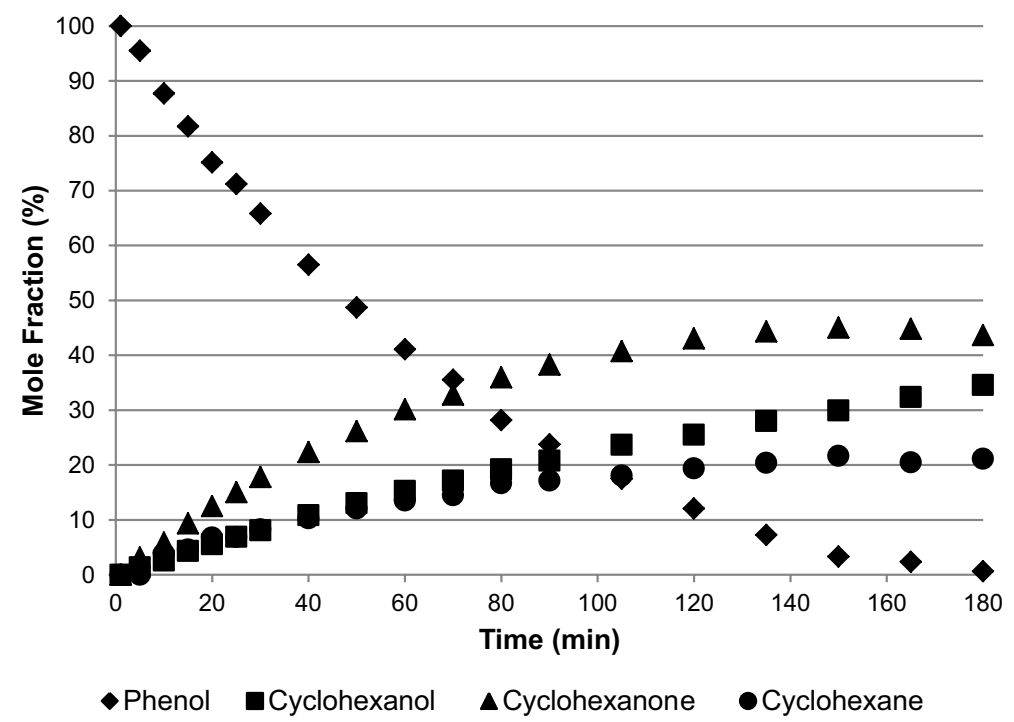

Fig. 3 Reaction profile of phenol hydrogenation. Conditions, $323 \mathrm{~K}, 10 \mathrm{mmol}, 3$ barg 


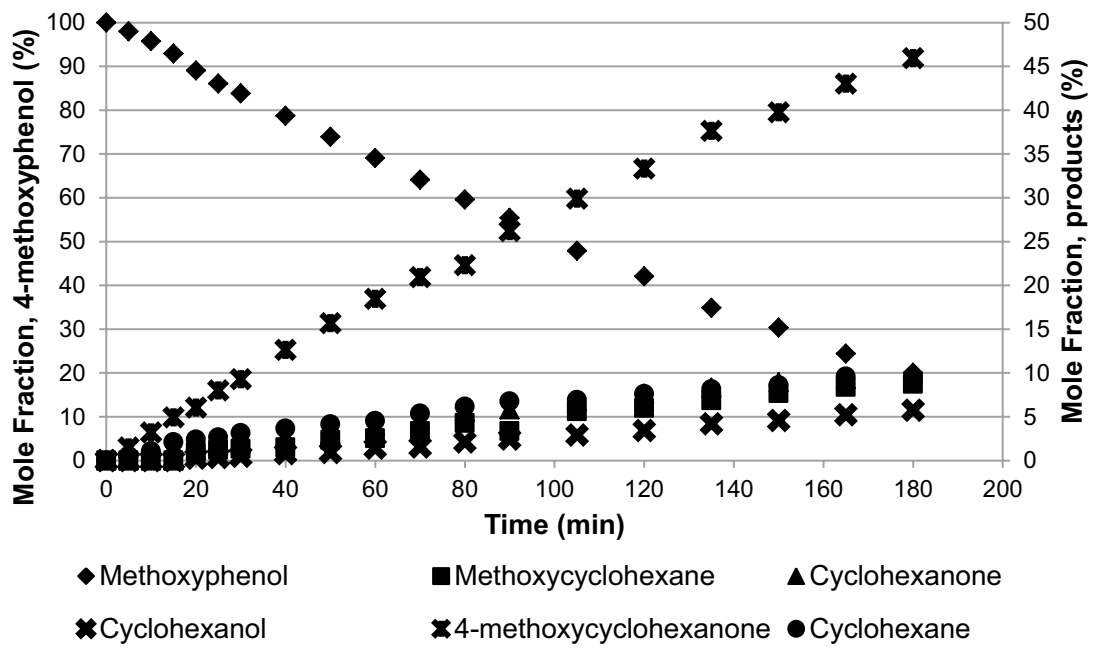

Fig. 4 Reaction profile of 4-methoxyphenol hydrogenation. Conditions, $323 \mathrm{~K}, 8 \mathrm{mmol}, 3 \mathrm{barg}$

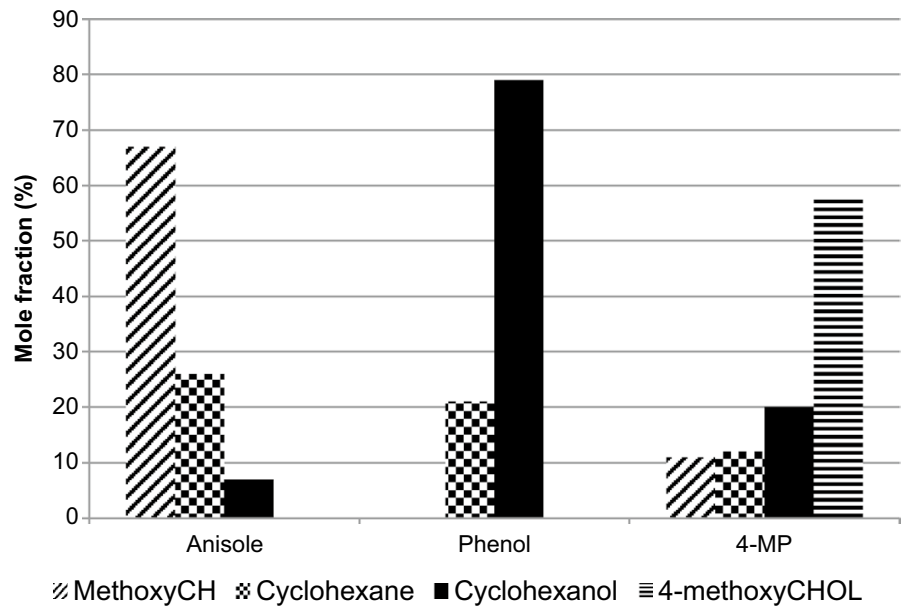

Fig. 5 Comparison of hydrogenation and HDO at $323 \mathrm{~K}$ with anisole, phenol and 4-methoxyphenol at $100 \%$ conversion (cyclohexanone and cyclohexanol are summed). Pressure 3 barg, 9 mmol. (Methox$\mathrm{yCH}$, methoxycyclohexane; 4-methoxyCHOL, 4-methoxycyclohexanol)

hydrogenolysis/hydrogenation from phenol to cyclohexane has been proposed by Hurff and Klein [27] to explain a high yield of cyclohexane.

The hydrogenation of 4-methoxyphenol gave 4-methoxycyclohexanone as the major product; no 4-methoxycyclohexanol was formed (Fig. 4). In contrast cyclohexanone and cyclohexanol were both formed but not 4-hydroxycyclohexanone or 1,4-dihydroxycyclohexane. At $343 \mathrm{~K}$ (Fig. 5) it is clear that cyclohexanone is hydrogenated to cyclohexanol but 4-methoxycyclohexanone is not hydrogenated 
to 4-methoxycyclohexanol even when all the 4-methoxyphenol has been consumed. Similar behavior has been observed when cyclohexanone and 4-methylcyclohexanone were co-hydrogenated over rhodium [31]. The difference in reactivity observed was deemed to be due to the greater cross sectional area of 4-methylcyclohexanone, which in adsorption from a binary mixture would ensure that the unsubstituted ketone would exceed the substituted one in surface concentration (unless interaction among adsorbed ketone molecules was negligible) [31]. In a competitive environment this difference in surface concentration may be responsible for the observed absence of hydrogenation of 4-methoxycyclohexanone, which has a much larger cross-sectional area than cyclohexanone. The products from 4-methoxyphenol hydrodeoxygenation allow a comparison of demethoxylation (formation of cyclohexanol) and dehydroxylation (formation of methoxycyclohexane), Scheme 2. It is clear that the catalyst was more selective for demethoxylation (yield of cyclohexanol + cyclohexanone, 16\% c.f. yield of methoxycyclohexane, 9\%, Fig. 4). This reflects the difference in bond energies between the $\mathrm{Ar}-\mathrm{OCH}_{3}$ bond $\left(\sim 419 \mathrm{~kJ} \mathrm{~mol}^{-1}\right)$ and the $\mathrm{Ar}-\mathrm{OH}$ bond $\left(\sim 431 \mathrm{~kJ} \mathrm{~mol}^{-1}\right)$. This behavior is reflected in the HDO literature [32] where demethoxylation has been found to be the favored process. Note that the absence of 4-hydroxycyclohexanone and 1,4-dihydroxycyclohexane indicate that there was no $\mathrm{ArO}-\mathrm{CH}_{3}$ bond breaking in 4-methoxyphenol hydrogenation in contrast to that found with anisole, where $\mathrm{ArO}-\mathrm{CH}_{3}$ bond breaking was observed, although to a lesser extent than $\mathrm{Ar}-\mathrm{OCH}_{3}$ bond breaking. This suggests that there is a difference in the bonding of anisole and 4-methoxyphenol. With 4-methoxyphenol we propose that the methyl group is not in contact with the surface but is angled away from the surface ensuring that the $\mathrm{O}-\mathrm{CH}_{3}$ remains intact. Cyclohexane was also formed, this is in contrast to a recent hydrogenation study of 4-methoxyphenol over nickel catalysts [33] at $423 \mathrm{~K}$ and $\sim 40$ bar, where only 4-methoxycyclohexanol, cyclohexanol and 4-methoxycyclohexanone were formed.

The difference between hydrogenation and hydrogenolysis in the reactions of the three reagents is shown in Fig. 5, where it can be seen that the system that was most selective to HDO was hydrogenation of 4-methoxyphenol, with breakage of $\mathrm{Ar}-\mathrm{OH}$ and $\mathrm{Ar}-\mathrm{OCH}_{3}$ bonds. With anisole there was breaking of $\mathrm{Ar}-\mathrm{OCH}_{3}$ and $\mathrm{ArO}-\mathrm{CH}_{3}$ bonds. It was possible to determine the rate constant for the production of cyclohexane from each of the aromatic species and $\mathrm{k}$ values of $19.5 \mathrm{~min}^{-1}, 3.1 \mathrm{~min}^{-1}$ and $0.9 \mathrm{~min}^{-1}$ were calculated for anisole, phenol and 4-methoxyphenol respectively, reinforcing the ease of breaking the $\mathrm{Ar}-\mathrm{OCH}_{3}$ bond relative to the $\mathrm{Ar}-\mathrm{OH}$ bond.

\section{Competitive reactions}

The competitive hydrogenations of phenol, anisole and 4-methoxyphenol were investigated. The compounds were tested in pairs and also with all three reactants present (Figs. 6, 7, 8, 9). The first order rate constants are reported in Table 2. Compared to the single reaction, the first order rate constants were significantly reduced for anisole. For phenol the rate constant was also reduced, when anisole was present but increased slightly when 4-methoxyphenol was present, whereas for 4-methoxyphenol the first order rate constant increased under competitive reaction, except 


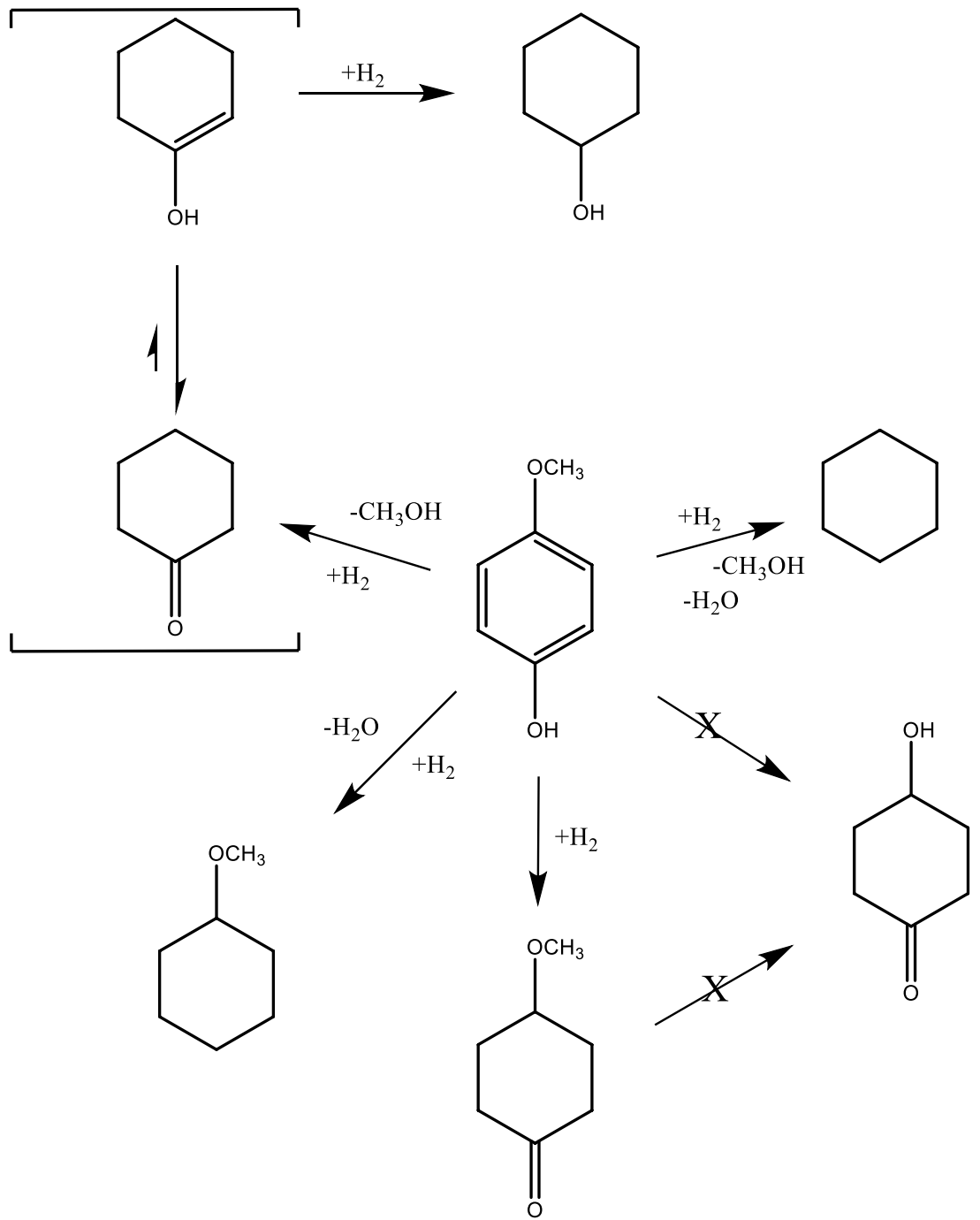

Scheme 2 Hydrogenation and hydrodeoxygenation of 4-methoxyphenol

when all three reactants were present. As well as changes in activity there was also direct inhibition under competitive conditions. When all three reactants were hydrogenated together anisole reacted immediately, however phenol hydrogenation was delayed by $5 \mathrm{~min}$, while 4-methoxyphenol hydrogenation was inhibited for $25 \mathrm{~min}$. When the systems are reacted in pairs similar delays are noted. This indicates a strength of adsorption order of anisole $>$ phenol $>4$-methoxyphenol.

The results from the competitive hydrogenation of the three substrates were revealing in terms of adsorption and mechanism. When phenol and anisole were competitively hydrogenated the rate of reaction decreased for both reactants (almost 


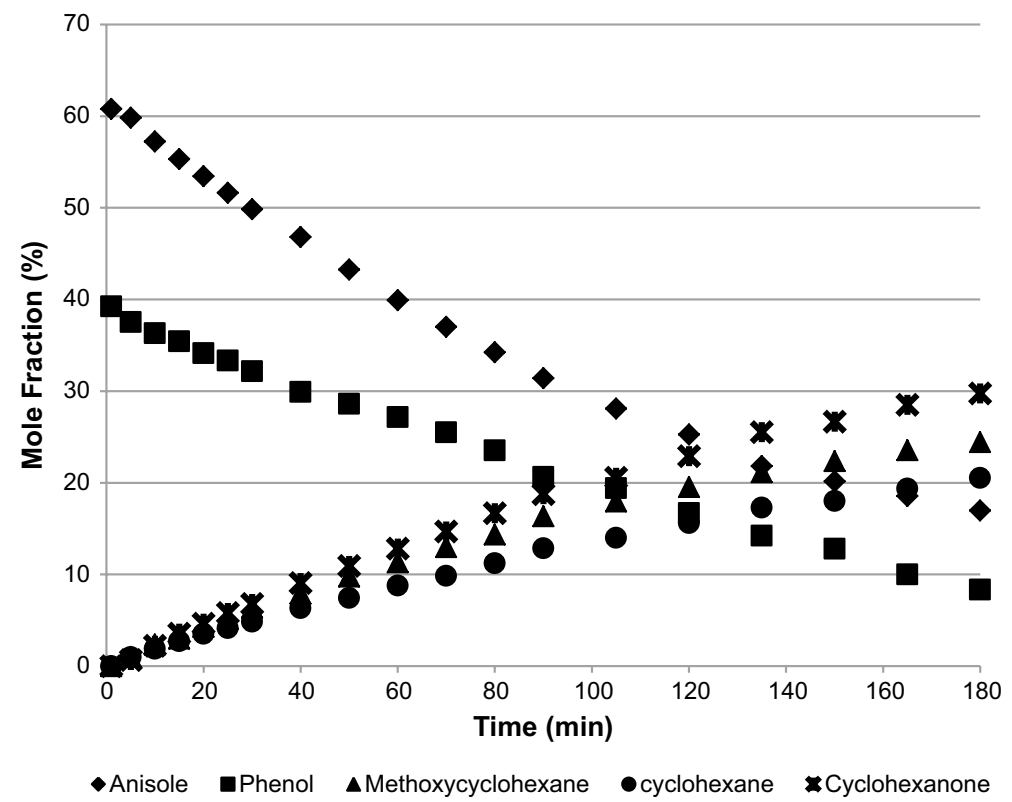

Fig. 6 Competitive reaction of anisole and phenol. Conditions: $323 \mathrm{~K}, 3$ barg, concentrations as per single reactions

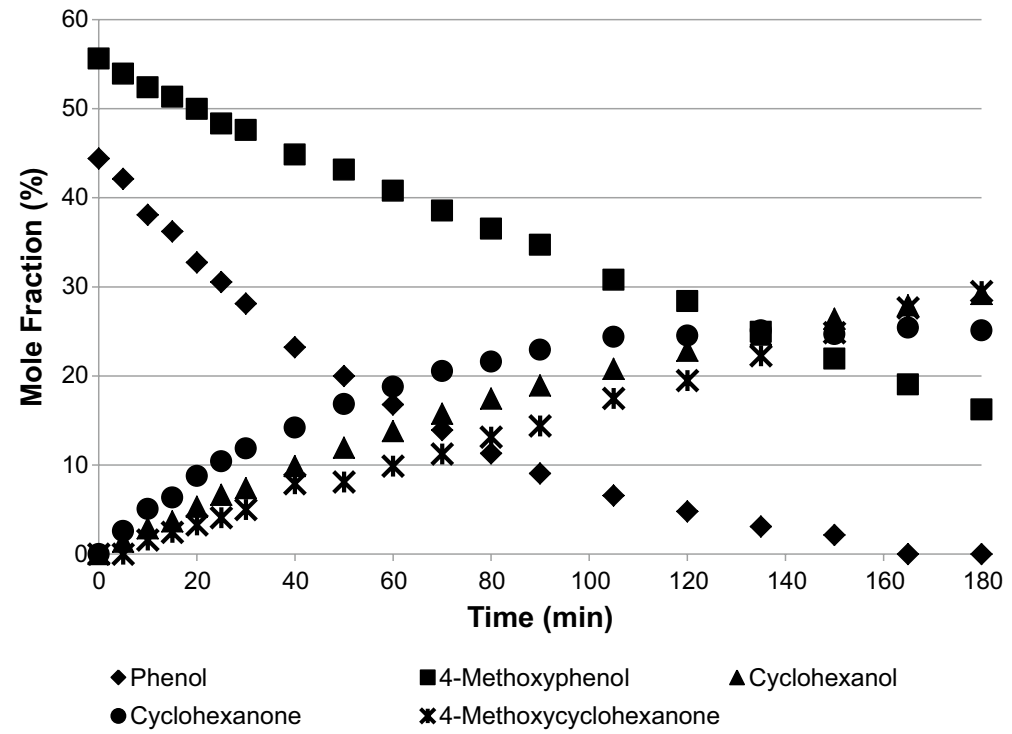

Fig. 7 Competitive reaction of 4-methoxyphenol and phenol. Conditions: $323 \mathrm{~K}, 3$ barg, concentrations as per single reactions 


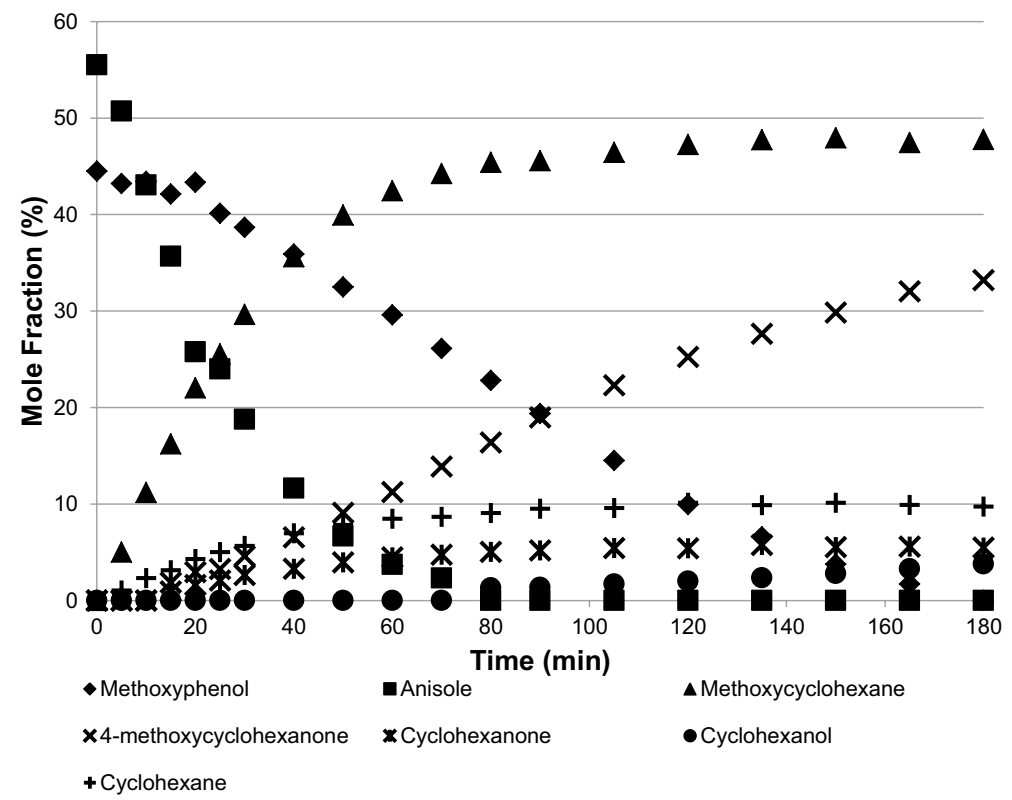

Fig. 8 Competitive reaction of 4-methoxyphenol and anisole. Conditions: $323 \mathrm{~K}, 3 \mathrm{barg}$, concentrations as per single reactions

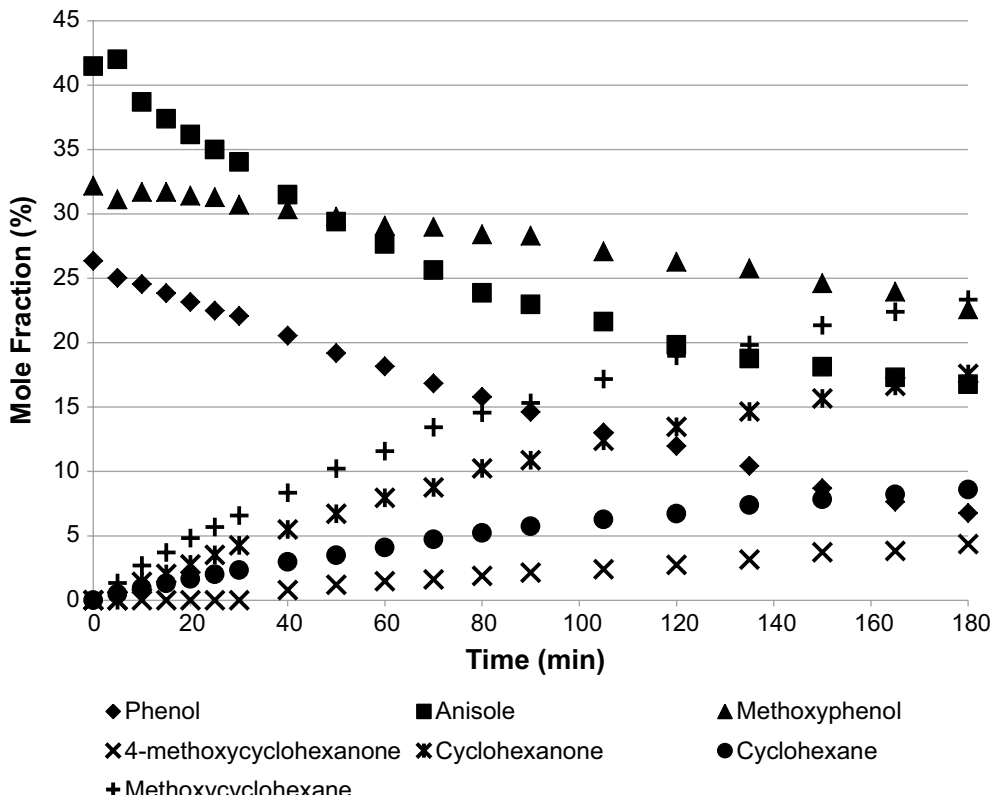

Fig. 9 Competitive reaction of 4-methoxyphenol, phenol and anisole. Conditions: $323 \mathrm{~K}, 3$ barg, concentrations as per single reactions 
Table 2 Competitive hydrogenation at $323 \mathrm{~K}, 3$ barg and $\sim 9 \mathrm{mmol}$

\begin{tabular}{lrrrrl}
\hline Reactant & \multicolumn{5}{l}{ First order rate constant, $\mathrm{k}\left(\mathrm{min}^{-1}, \times 10^{-3}\right)$} \\
\cline { 2 - 6 } & Single reactant & Phenol/anisole & Phenol/4-MP & Anisole/4-MP & $\begin{array}{l}\text { Phenol/anisole/4- } \\
\text { MP }\end{array}$ \\
\hline Phenol & $14.7 \pm 0.2$ & $8.9 \pm 0.1$ & $16.6 \pm 0.2$ & & $6.8 \pm 0.1$ \\
Anisole & $74.8 \pm 4.8$ & $10.0 \pm 0.1$ & & $27.4 \pm 2.9$ & $7.6 \pm 0.2$ \\
4-Methoxyphenol & $6.4 \pm 0.1$ & & $13.9 \pm 0.5$ & $25.1 \pm 0.8$ & $2.0 \pm 0.1$ \\
\hline
\end{tabular}

a4-MP, 4-methoxyphenol

an order of magnitude decrease in rate for anisole and factor of two decrease in rate for phenol). The hydrogenation of phenol was slightly inhibited initially and no reaction occurred for the first $5 \mathrm{~min}$, whereas anisole reacted immediately. Nevertheless both species were co-adsorbed and the rate of anisole hydrogenation dropped more significantly than phenol hydrogenation. No cyclohexanol was formed as the presence of anisole inhibited re-adsorption of cyclohexanone and subsequent hydrogenation. This indicated that there was no direct hydrogenation route from phenol to cyclohexanol and that cyclohexanol was formed as a secondary product of cyclohexanone hydrogenation (Scheme 3). The production of cyclohexane was interesting as analysis of the conversion of phenol and anisole and the yields of cyclohexanone and methoxycyclohexane, revealed that the entire cyclohexane yield comes from

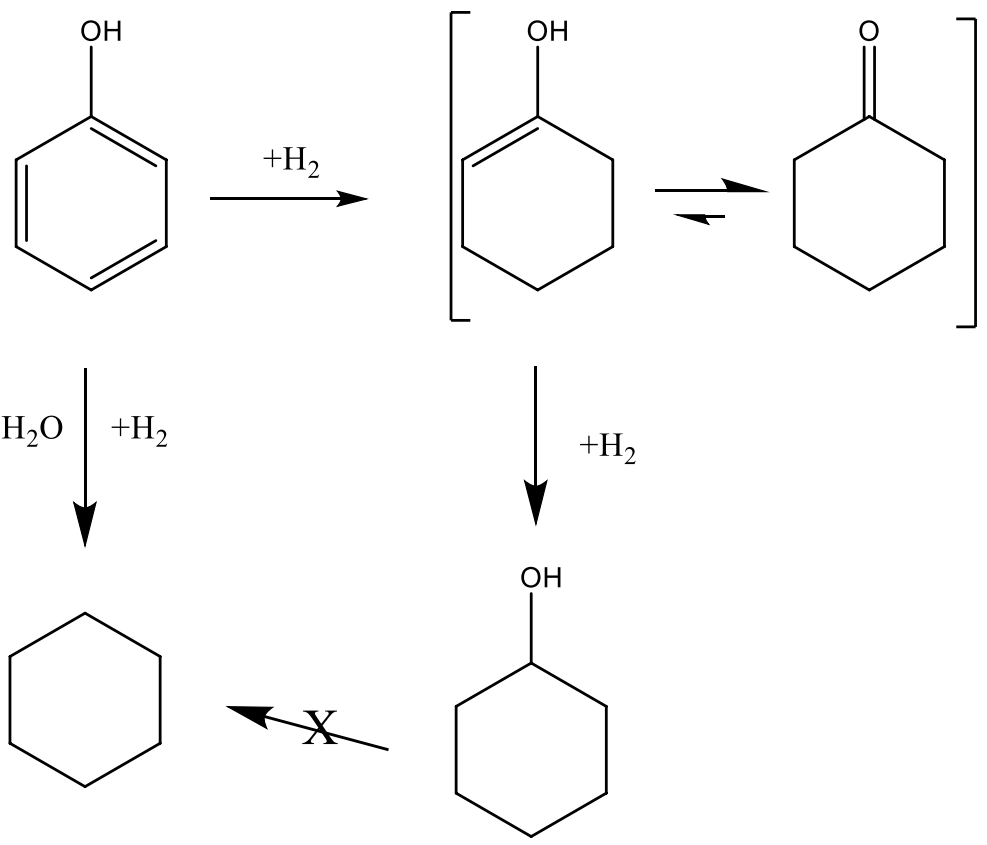

Scheme 3 Hydrogenation and hydrodeoxygenation of phenol 
anisole (This is shown in Figs. a and $b$ in the supplementary information). Therefore the hydrogenolysis of phenol to cyclohexane was completely inhibited by anisole. It has been suggested that the route to cyclohexane from phenol is via cyclohexanol [13] and hence if cyclohexanol is not formed it would not be possible to form cyclohexane. However other authors [27] have suggested direct conversion of phenol to cyclohexane and we have shown that cyclohexanol was stable under these conditions over this catalyst (Fig. 1) and did not form cyclohexane [34]. Therefore the absence of cyclohexane was not related to the absence of cyclohexanol. Nevertheless cyclohexane was not formed from phenol in the presence of anisole and it is possible that this was due to a change in the adsorbed state. Two adsorbed states have been proposed for phenol $[35,36]$ with a co-planar adsorption leading to cyclohexanone. It is possible that this adsorbed state also leads to cyclohexane. If the co-planar adsorbed state was changed to the non-planar mode, possibly due to surface crowding in a competitive environment, then $\mathrm{HO}-\mathrm{Ph}$ hydrogenolysis would be much less likely.

The competitive hydrogenation of phenol and 4-methoxyphenol (Fig. 7) gave a higher rate of reaction for both phenol and 4-methoxyphenol compared to the single reactants. Such behavior has been observed before for competitive hydrogenation of alkynes and alkenes [37] and may be related to changes in either surface hydrogen concentration or reconstruction of the surface. Surprisingly no cyclohexane is formed even though it was produced by both reactants when reacted on their own. However cyclohexanone/cyclohexanol were formed from both phenol (by hydrogenation) and 4-methoxyphenol (by hydrogenolysis) indicating that demethoxylation was occurring. Therefore the lack of cyclohexane formation was due to the inability of the system to break the Ar-OH bond. Note that this result reinforces the conclusion that cyclohexane was not produced from cyclohexanol. Why the $\mathrm{Ar}-\mathrm{OH}$ bond can no longer be broken could be due to geometric factors. There is now competition for sites with two aromatic species present and it is likely that both species would be affected, however $\mathrm{Ar}-\mathrm{OCH}_{3}$ bond breaking still occurs and it seems unlikely that the site requirement for this hydrogenolysis reaction is less than that required for $\mathrm{Ar}-\mathrm{OH}$ bond hydrogenolysis. Another possibility is a change in the mode of adsorption and that this inhibits Ar-OH hydrogenolysis but this must apply to both phenol and 4-methoxyphenol. Different modes of adsorption have been detected for phenol but there is no literature concerning 4-methoxyphenol, nevertheless this seems the most likely reason for the inhibition of Ar-OH hydrogenolysis.

The competitive reaction between anisole and 4-methoxyphenol revealed a number of interesting features (Fig. 8). Anisole inhibited the reaction of 4-methoxyphenol for $\sim 10 \mathrm{~min}$. Initially only methoxycyclohexane and cyclohexane were formed from anisole, which was different from non-competitive hydrogenation, where cyclohexanone was also formed from anisole. The absence of cyclohexanone formed from anisole is surprising as it implies that the 4-methoxyphenol is influencing the reactivity of the anisole even though it is not reacting. This type of behaviour has been seen in transhydrogenation [38] but is not commonly reported. It is clear that the demethoxylation reaction of anisole was occurring giving cyclohexane but that the demethylation reaction was inhibited. This suggests that the anisole is adsorbed flat with the ring and oxygen interacting with the surface but with 
the methyl group pointing up away from the surface. This mode of adsorption has been proposed to explain the results of deuterium exchange where no deuterium was found in the methyl group [26]. This would suggest two modes of adsorption for anisole, one with the methyl group interacting with the surface, which can lead to cyclohexanone/ol, and another mode where the methyl group is not interacting with the surface, leading to cyclohexane. Once 4-methoxyphenol started to hydrogenate, cyclohexanone was formed along with 4-methylcyclohexanone. As when 4-methoxyphenol was hydrogenated in the absence of anisole, no 4-methoxycyclohexanol was produced, while cyclohexanol was only produced after anisole had been completely hydrogenated. Cyclohexane was only produced from anisole, once all anisole had reacted the yield of cyclohexane plateaued (like that of methoxycyclohexane, Fig. 8).

When all three reactants were hydrogenated simultaneously, the rate of hydrogenation for each reactant was significantly reduced (Fig. 9 and Table 2). The rate constant for anisole was $0.0076 \mathrm{~min}^{-1}$ in the competitive reaction, compared to $0.0748 \mathrm{~min}^{-1}$ for anisole on its own-a drop of nearly an order of magnitude. In the pair combinations the rate of 4-methoxyphenol hydrogenation was increased but it was reduced when all three reactants were present. Indeed the hydrogenation of 4-methoxyphenol did not appear to start for $\sim 25 \mathrm{~min}$, when 4-methoxycyclohexanone was produced: cyclohexanone production also had a short delay ( $5 \mathrm{~min})$ before being generated from phenol. This inhibition was expected from the results of the pair reactions. What was also noticeable was that when anisole was present the behavior of phenol was altered. In competitive reactions with anisole the conversion of phenol with time was linear, whereas in reactions without anisole the conversion of phenol followed an exponential decay. This suggests that the order of reaction in phenol had changed, indicating that anisole modified the adsorption of phenol. The absence of alcohol products was expected due to the presence of anisole throughout the reaction. However analysis of the product distribution at $180 \mathrm{~min}$ indicated that cyclohexane was produced from all three reactants. This is in contrast to the pair reactions where cyclohexane was only produced from anisole. Therefore the product mix for the competitive reactions cannot be determined by analyzing the reactions of single components or indeed the pair reactions. This has significant implications for research using a model compound as an exemplar of a mixed reaction feed.

\section{Deuterium reactions}

The effect of changing hydrogen for deuterium was examined for each reactant. The reaction profiles are presented in the supplementary data. The overall rate constants for both hydrogen and deuterium reactions are reported in Table 3. For both anisole and phenol deuteration was slower than hydrogenation resulting in a positive kinetic isotope effect (KIE), however 4-methoxyphenol reacted faster when deuterium was present. Determination of individual KIEs for each reaction occurring in the 4-methoxyphenol hydrogenation reaction revealed that the hydrogenation of 4-methoxyphenol to 4-methoxycyclohexanone had an inverse KIE, while surprisingly production of cyclohexane revealed no KIE. This behavior was similar to that observed 
Table 3 Rate constants for hydrogenation and deuteration at $323 \mathrm{~K}$ and 3 barg pressure

\begin{tabular}{llll}
\hline & \multicolumn{2}{l}{ Reactant } & \\
\cline { 2 - 4 } & Anisole & Phenol & 4-Methoxyphenol \\
\hline $\mathrm{k}_{\mathrm{H}}\left(\mathrm{min}^{-1}, \times 10^{-3}\right)$ & $74.8 \pm 4.8$ & $14.7 \pm 0.2$ & $6.4 \pm 0.1$ \\
$\mathrm{k}_{\mathrm{D}}\left(\mathrm{min}^{-1}, \times 10^{-3}\right)$ & $46.0 \pm 4.6$ & $11.0 \pm 0.1$ & $8.2 \pm 0.3$ \\
$\mathrm{k}_{\mathrm{H}} / \mathrm{k}_{\mathrm{D}}$ & 1.6 & 1.3 & 0.8 \\
\hline
\end{tabular}

with the ring hydrogenation of alkylaromatics, where an inverse KIE was observed [39]. It was suggested that this was a secondary inverse KIE, which could be related to the change in hybridization of the carbon $(\mathrm{C}-\mathrm{H})$ from $\mathrm{sp}^{2}$ to $\mathrm{sp}^{3}$ as would be the case in hydrogenation of the aromatic ring [39]. There are few other examples of this in the literature but an inverse KIE was also observed with graphene hydrogenation [40].

The hydrogenation of anisole was faster than the deuteration and an overall KIE of 1.6 was obtained. Detailed analysis revealed that the selectivity had changed and determination of the KIE for each product gave values of 2.0 for cyclohexane, 1.6 for methoxycyclohexane and 1.3 for cyclohexanol. Therefore for anisole, ring hydrogenation showed a positive KIE in contrast to 4-methoxyphenol, which gave a negative KIE. Ring hydrogenation of phenol also exhibited a positive KIE (1.3); this value was also obtained for each product. Why there is this difference between the ring hydrogenation of 4-methoxyphenol, and anisole and phenol is not immediately apparent.

\section{Conclusions}

The hydrogenation of anisole, phenol and 4-methoxyphenol was studied in the liquid phase over a $\mathrm{Rh} /$ silica catalyst. The rate of conversion of the reactants to products gave an order of anisole $\gg$ phenol $>4$-methoxyphenol with hydrogenation and hydrodeoxygenation products being produced. Anisole was converted to methoxycyclohexane, cyclohexane and cyclohexanone as primary products; cyclohexanone was only hydrogenated to cyclohexanol once all the anisole had been reacted, confirming a sequential route to cyclohexanol. Phenol was hydrogenated to cyclohexanone and cyclohexane but in contrast to anisole, phenol did not inhibit hydrogenation of cyclohexanone to cyclohexanol. Nevertheless competitive reactions between anisole and phenol confirmed that cyclohexanol was a secondary product from both reactants. The yield of cyclohexane, the hydrodeoxygenation (HDO) product, was $>20 \%$ from both reactants but was higher from anisole reflecting the lower $\mathrm{Ar}-\mathrm{OCH}_{3}$ bond strength relative to the $\mathrm{Ar}-\mathrm{OH}$ bond. Cyclohexane was formed directly from the aromatic species and not from cyclohexanol; this was clear from the anisole reaction and separate hydrogenation of cyclohexanone to cyclohexanol, which produced no cyclohexane [34]. Hydrogenation of 4-methoxyphenol was selective to 4-methoxycyclohexanone with no alcohol formation, while the hydrogenolysis products revealed that the rate of demethoxylation was almost twice that of dehydroxylation, 
in agreement with the reactions of anisole and phenol. A comparative strength of adsorption was determined from competitive hydrogenation and gave an order of anisole $>$ phenol $>4$-methoxyphenol. Competitive reaction was found to significantly inhibit HDO and stopped the formation of cyclohexane from phenol and 4-methoxyphenol suggesting a change in the mode of adsorption in the presence of a more strongly adsorbed species (anisole). In contrast anisole produced cyclohexane even in a competitive environment. An increased the rate of hydrogenation for 4-methoxyphenol was observed for competitive reactions with phenol and anisole even though the rates for phenol and anisole decreased. 4-methoxyphenol had the weakest adsorption but nevertheless influenced the hydrogenation reactions of phenol and anisole. When all three aromatics were present cyclohexane was produced by all three reactants, in contrast to that found with pair reactions. Replacing hydrogen with deuterium revealed an inverse kinetic isotope effect for ring hydrogenation of 4-methoxyphenol but a positive KIE for all other reactions.

From these results it is clear that competitive hydrogenation reactions are highly complex and are not easily relatable to single molecule hydrogenation. Indeed the reaction behavior when three species were present was not predictable from single or pair reactions.

Acknowledgements The authors would like to thank King Abdul-Aziz City for Science and Technology (KACST) for a studentship (FA).

Open Access This article is distributed under the terms of the Creative Commons Attribution 4.0 International License (http://creativecommons.org/licenses/by/4.0/), which permits unrestricted use, distribution, and reproduction in any medium, provided you give appropriate credit to the original author(s) and the source, provide a link to the Creative Commons license, and indicate if changes were made.

\section{References}

1. Mäki-Arvela P, Murzin DY (2017) Catalysts 7:265-305

2. Shi Y, Xing E, Wu K, Wang J, Yang M, Wu Y (2017) Catal Sci Technol 7:2385-2415

3. Mortensen PM, Grunwaldt JD, Jensen PA, Knudsen KG, Jensen AD (2011) Appl Catal A 407:1-19

4. Lup ANK, Abnisa F, Daud WMAW, Aroua MK (2017) Appl Catal A 541:87-106

5. Bouxin FP, Zhang X, Kings IN, Lee AF, Simmons MJH, Wilson K, Jackson SD (2017) Appl Catal A 539:29-37

6. Lin CJ, Huang SH, Lai NC, Yang CM (2015) ACS Catal 5:4121-4129

7. Tobicik J, Cerveny L (2003) J Mol Catal A 194:249-254

8. Velu S, Kapoor MP, Inagaki S, Suzuki K (2003) Appl Catal A 245:317-331

9. Giraldo L, Bastidas-Barranco M, Moreno-Piraján JC (2014) Molecules 19:20594-20612

10. Scire S, Minico S, Crisafulli C (2002) Appl Catal A 235:21-31

11. Park C, Keane MA (2003) J Colloid Interface Sci 266:183-194

12. Neri G, Visco AM, Donato A, Milone C, Malentacchi M, Gubitosa G (1994) Appl Catal A 110:49-59

13. Pérez Y, Fajardo M, Corma A (2011) Catal Commun 12:1071-1074

14. Zhu YH, Karen Tang Y, Narayan SH (2013) Applications of ionic liquids in lignin chemistry. In: Kadokawa JI (ed) New aspects for the future I, Japan, vol 13. Croatia, InTech, pp 315-346

15. Fonseca GS, Umpierre AP, Fichtner PFP, Texeira SR, Dupont J (2003) Chem Eur J 9:3263-3269

16. Mevellec V, Nowicki A, Roucoux A, Dujardin C, Granger P, Payen E, Philippot K (2006) New J Chem 30:1214-1219

17. Lu F, Liu J, Xu J (2006) Adv Synth Catal 348:857-861 
18. Denicourt-Nowicki A, Leger B, Roucoux A (2011) Phys Chem Chem Phys 13:13510-13517

19. Schulz J, Roucoux A, Patin H (1999) Chem Commun 6:535-536

20. Widegren JA, Finke RG (2002) Inorg Chem 41:1558-1572

21. Hubert C, Denicourt-Nowicki A, Guégan JP, Roucoux A (2009) Dalton Trans 36:7356-7358

22. Neumann D, Ritzer J, Effenberger G (2013) US patent 8802897, assigned to ALESSA Chemie GMBH

23. Barthe L, Denicourt-Nowicki A, Roucoux A, Philippot K, Chaudret B, Hemati M (2009) Catal Commun 10:1235-1239

24. Meng Q, Hou M, Liu H, Song J, Han B (2017) Nat Commun 8:14190

25. Gamliel DP, Karakalos S, Valla JA (2018) Appl Catal A 559:20-29

26. Anderson RB, Kemball C (1966) J Catal 6:82-91

27. Hurff SJ, Klein MT (1983) Ind Eng Chem Fundam 22:426-430

28. Rode CV, Joshi UD, Sato O, Shira M (2003) Chem Commun 2003:1960-1961

29. Wang H, Zhao F, Fujita SI, Arai M (2008) Catal Commun 9:362-368

30. Teles CA, Rabelo-Neto RC, de Lima JR, Mattos LV, Resasco DE, Noronha FB (2016) Catal Lett 146:1848-1857

31. Tanaka K, Takagi Y, Nomura O, Kobayashi I (1974) J Catal 35:24-33

32. Bouxin FP, Zhang X, Kings IN, Lee AF, Simmons MJH, Wilson K, Jackson SD (2018) Org Proc Res Dev 22:1586-1589

33. She T, Chu X, Zhang H, Dong J, Niu L, Lan X, Bai G (2018) J Nanopart Res 20:224-235

34. Alshehri F, (2017) Thesis, University of Glasgow

35. Neri G, Visco AM, Donato A, Milone C, Malentacchi M, Gubitosa G (1994) Appl Catal A 110:49-59

36. Chen YZ, Liaw CW, Lee LI (1999) Appl Catal A 177:1-8

37. Jackson SD, Kelly GJ (1997) Curr Top Catal 1:47-59

38. Garba MD, Jackson SD (2017) Appl Petrochem Res 7:1-8

39. Alshehri F, Weinert HM, Jackson SD (2017) Reac Kinet Mech Cat 122:699-714

40. Paris A, Verbitskiy N, Nefedov A, Wang Y, Fedorov A, Haberer D, Oehzelt M, Petaccia L, Usachov D, Vyalikh D, Sachdev H, Wöll C, Knupfer M, Büchner B, Calliari L, Yashina L, Irle S, Grüneis A (2013) Adv Funct Mater 23:1628-1635

Publisher's Note Springer Nature remains neutral with regard to jurisdictional claims in published maps and institutional affiliations.

\section{Affiliations}

\section{Feras Alshehri ${ }^{1,2} \cdot$ Clement Feral $^{1} \cdot$ Kathleen Kirkwood $^{1} \cdot$ S. David Jackson ${ }^{1}$ (])}

S. David Jackson

david.jackson@glasgow.ac.uk

1 School of Chemistry, Centre for Catalysis Research, University of Glasgow, Glasgow, Scotland G12 8QQ, UK

2 Present Address: King Abdulaziz City for Science and Technology, King Abdullah Rd, Ar Raid, Riyadh 12354, Saudi Arabia 